\title{
Comprehensive Experimental analysis and sustainability Assessment of Machining Nimonic 90 using Ultrasonic-Assisted-Turning Facility
}

\author{
Jay Airao a , Navneet Khanna ${ }^{\mathrm{a}, *}$, Anish Roy ${ }^{\mathrm{b}}$, Hussien Hegab ${ }^{\mathrm{c}, *}$ \\ a,M.Tech student, Department of Mechanical Engineering, Institute of Infrastructure, Technology, Research, and \\ Management, Ahmedabad, India 380026. (jayairao.airao@gmail.com) \\ aDepartment of Mechanical Engineering, Institute of Infrastructure, Technology, Research, and Management, \\ Ahmedabad, India 380026. (navneetkhanna@iitram.ac.in) \\ ${ }^{\mathbf{b}}$ Wolfson School of Mechanical and Manufacturing Engineering, Loughborough University, Loughborough, \\ Leicestershire LE11 3TU, UK. (a.roy3@lboro.ac.uk) \\ 'Mechanical Design and Production Engineering Department, Cairo University, Giza 12613, Egypt. \\ (hussien.hegab@uoit.ca) \\ *Corresponding Author: (Email: hussien.hegab@uoit.ca, navneetkhanna@iitram.ac.in)
}

\begin{abstract}
Many techniques have been developed to improve the machinability of aeronautical materials titanium and nickel-based alloys such as ultrasonic-assisted turning, laser-assisted turning, cryogenic assisted turning, etc. This collaborative scientific investigation presents the steps taken to gain insight into the phenomena of machining Nimonic 90 (a nickel-based alloy) alloy using ultrasonically assisted turning. The cutting speed, feed rate, depth-of-cut, and frequency are taken as input parameters and average surface roughness $\left(R_{a}\right)$, power consumption $(P)$, and chip formation are considered as output parameters. The experiments are carried out with the full factorial design. The UAT (Ultrasonic assisted turning) process gives a significant improvement in average surface roughness, power consumption because of the intermittent cutting action of the cutting tool. UAT process shows a 70-80\% reduction in average surface roughness $\left(R_{a}\right)$ and a $6-15 \%$ reduction in power consumption as compared to CT (conventional turning) process. Ultrasonically assisted turning also resulted in the thin and smoother chips as compared to CT process which helps to achieve a more superior machining effect. Finite element modeling shows that the quasi-static nature of the stress induced in UAT process leads to lower force and ultimately lower power generation. Moreover, a sustainability assessment model is implemented to investigate the effect of UAT in terms of machining performance as well as sustainability effectiveness in a single integrated approach. The novelty of this work lies in providing an integrated concept that combines experimental analysis and sustainability assessment when using ultrasonic vibrational energy during turning of Nimonic 90.
\end{abstract}

Keywords: Ultrasonically assisted turning (UAT), Nimonic 90, Surface roughness, Power consumption, Finite Element Modeling, Sustainability assessment 


\section{Terminology}

$\begin{array}{ll}\text { UAT } & \text { Ultrasonically assisted turning } \\ \text { CT } & \text { Conventional turning } \\ \text { TWCR } & \text { Tool work-piece contact ratio } \\ \text { FEM } & \text { Finite element modeling } \\ \text { DOC } & \text { Depth of cut }(\mathrm{mm}) \\ \text { MRR } & \text { Material removal rate }\left(\mathrm{mm}^{3} / \mathrm{s}\right) \\ \mathrm{m} / \mathrm{min} & \text { meter per minute } \\ \mathrm{mm} / \mathrm{rev} & \text { millimeter per revolution } \\ R_{a} & \text { Average surface roughness }(\mu \mathrm{m}) \\ P & \text { Power consumption }(\mathrm{W}) \\ F & \text { Frequency }(\mathrm{kHz}) \\ f & \text { Feed rate }(\mathrm{mm} / \mathrm{rev}) \\ V & \text { Cutting speed }(\mathrm{m} / \mathrm{min})\end{array}$

\section{Introduction}

Advance materials such as titanium alloys and nickel-based superalloys are employed in widespread applications such as aerospace, automobile, nuclear, chemical industries, biomedical applications, etc. [1]. Conventional machining of these alloys leads to rapid tool wear and high tool temperatures at relatively low cutting speeds due to their poor machinability. Nimonic-90, one of the Nickel base superalloy, is found to be difficult to machine due to above mentioned characteristics [2]. Several researches have been carried out to improve the machinability of Nimonic-90 by modifying/assisting the machining techniques such as minimum quantity lubrication (MQL) assisted turning [3, 4], nanoparticle-based MQL and cryogenic assisted machining [5], ultrasonic assisted turning [6], cryogenic-ultrasonic assisted turning [7], etc. Moreover, to analyze the machinability of Nimonic, different non-conventional processes have also been carried out such as Electro discharge machining [8], wire-electro discharge machining [9], laser beam machining, etc. Among all the above mentioned techniques, in the present research, UAT technique has been developed to further analyze the machinability of Nimonic-90. Ultrasonically assisted turning (UAT) is a hybrid machining process in which ultrasonic vibrations are superimposed on the cutting tool during the cutting action. The vibrating cutting tool interacts with the work-piece directly and cuts the material using a microchipping process [10].

Ahmed et al. [11] reported that the tensile residual stress in a conventional turning leads to failure and reduces the lifespan of the component. It was also pointed out by Maurotto et al. [12] with studies related to the machinability of Ti-15333 and Ni-625 alloys that due to the constant contact and separation of the tool during machining in a UAT, there was a significant reduction in cutting forces. Ahmed et al. [13] found that the 
cutting forces induced during CT were $130 \mathrm{~N}$ to $140 \mathrm{~N}$ whereas, in UAT, the cutting force ranges from $60 \mathrm{~N}$ to $95 \mathrm{~N}$. Maurotto et al. [14] observed a reduction of 70-75\% in the tangential force while machining of Ti15333 and Ni-625, which was claimed to be due to ultrasonic softening in the Ti-base alloys. It was also analyzed that the cutting force was more sensitive to the cutting speed in UAT as compared to CT process [15]. Muhammad et al. [16, 17] developed a hot ultrasonically assisted turning (HUAT) setup for aged Ti 15333 alloy, and an enhanced reduction in the cutting force was observed. W. Bai et al. [18] observed a reduction of around $44.3 \%$ in $R_{a}$ with WC tool in case of UAT as compared to CT of metal-matrix composite. Furthermore, Feyzi et al. [19] concluded that there was a $7-14 \%$ reduction in cutting force and a $9-14 \%$ reduction in flank wear in hybrid (CT+UAT) machining.

Surface roughness is a crucial factor that has an effect on machined components [20]. Maurotto et al. [21] showed significant improvements in surface roughness and cutting force in UAT of Inconel-718 and Ti15333. Muhammad et al. [22] concluded that the value of surface finish increased by $50 \%$ while machining of $\alpha+\beta$ titanium alloy with UAT. Lin et al. [23] found that the $R_{a}$ was improved by $15 \%$ with high amplitude because of the ironing effect. Babitsky et al. [24] used the auto resonant control system to maintain the stable nonlinear resonant mode of vibration throughout the cutting process and analyzed the surface finish for Inconel-718. Patil et al. [25] analyzed that the chip formed during UAT showed less cutting force with minimal plastic deformation. Nath et al. [26] studied the effect of frequency, amplitude and cutting speed on the cutting force generated during the UAT. Flank wear was analyzed in the machining of Inconel-718 [27]. It has been seen that the tool life of CBN inserts increased by 7 to 8 times for UAT. Amini et al. [28] found that the increment in tool rotary speed resulted in a reduction of $R_{a}$ and cutting force in rotary turning, while its effect was insignificant in rotary ultrasonic assisted turning (UART). In addition, Habtamu et al. [29] observed a $25-40 \%$ reduction in $R_{a}$ and $20 \%$ reduction in flank wear when machining of Inconel-718 with the UAT process. Khanna et al [6] developed the CUAT (cryogenic-ultrasonic assisted turning) process, in which $29 \%$ reduction of surface roughness observed in machining Nimonic-90 due to ultrasonic vibration combined with cryogenic machining.

Reducing power consumption during machining can significantly improve the environmental metrics of a manufacturing system. Bhushan [30] optimized the parameters for minimum power consumption $(P)$ to improve the tool life behavior during machining of $7075 \mathrm{Al}$ alloy $\mathrm{SiC}$ particle composites. It was observed that $P$ increased with an increase in the cutting speed [31]. Carmita [32] found that the feed rate was the most significant factor followed by the depth of cut (DOC) and cutting speed $(V)$. Aman et al. [33] investigated the effects of cutting speed; feed rate, DOC on $P$ in CNC turning of AISI P-20 tool steel with the help of RSM and Taguchi techniques. Several studies have pointed out the difficulties in machining nickel-based alloys, however, most of them focused on the widely used Inconel 718 alloy. Limited studies are dealing with the machining of Nimonic 90 alloy which demonstrates its poor machinability which leads to higher manufacturing costs. In this work, UAT is employed during machining Nimonic 90 alloy and its performance is compared with CT under the same process conditions.

In addition, offering a sustainable machining process became an important requirement in any manufacturing enterprise. In order to accomplish a sustainable environment, defining and assessment of sustainability effectiveness should be clearly obtained. From the open literature [34], it is investigated that five main 
elements represent "the sustainability concept". These elements are; energy consumption, waste management, environmental impact, costs, as well as health-safety aspects. Thus, assessment of the machining processes by considering these elements is a very essential task to offer a sustainable machining environment.

Concerning UAT, following research gaps are identified and addressed in this study.

1) Analysis of the machinability of Nimonic-90 with UAT is less explored in the literatures.

2) Studies are often limited to analyze the cutting force and surface roughness for UAT process but analysis of power consumption has not been studied yet.

3) Very few studies are available which presented details on design and development of UAT set-up along with experimental and FEM analysis.

4) To the best of authors' knowledge, sustainability assessment of UAT has not been explored in the literature.

Thus, the present work seeks to address the above mentioned gaps with an aim to create sustainability assessment database for UAT and CT of Nimonic-90. The novelty of this work lies in providing an integrated concept that combines design and development of UAT set-up, experimental analysis, FEM modeling and sustainability assessment during UAT of Nimonic 90.

\section{Experimental procedure}

\subsection{Experimental set-up}

Machinability studies in UAT of Nimonic 90 were performed on an in-house developed UAT set-up on a lathe as shown in Fig.1. The UAT set-up includes a frequency generator, piezoelectric transducer, and horn. The frequency generator generates the electrical signal which is converted into mechanical vibrations by a piezoelectric transducer. These mechanical signals propagate through the ultrasonic horn to the cutting tool. The primary objective of the ultrasonic horn is to amplify the vibrations to reasonable amplitudes. Well known relations exist which are used to facilitate horn design. 


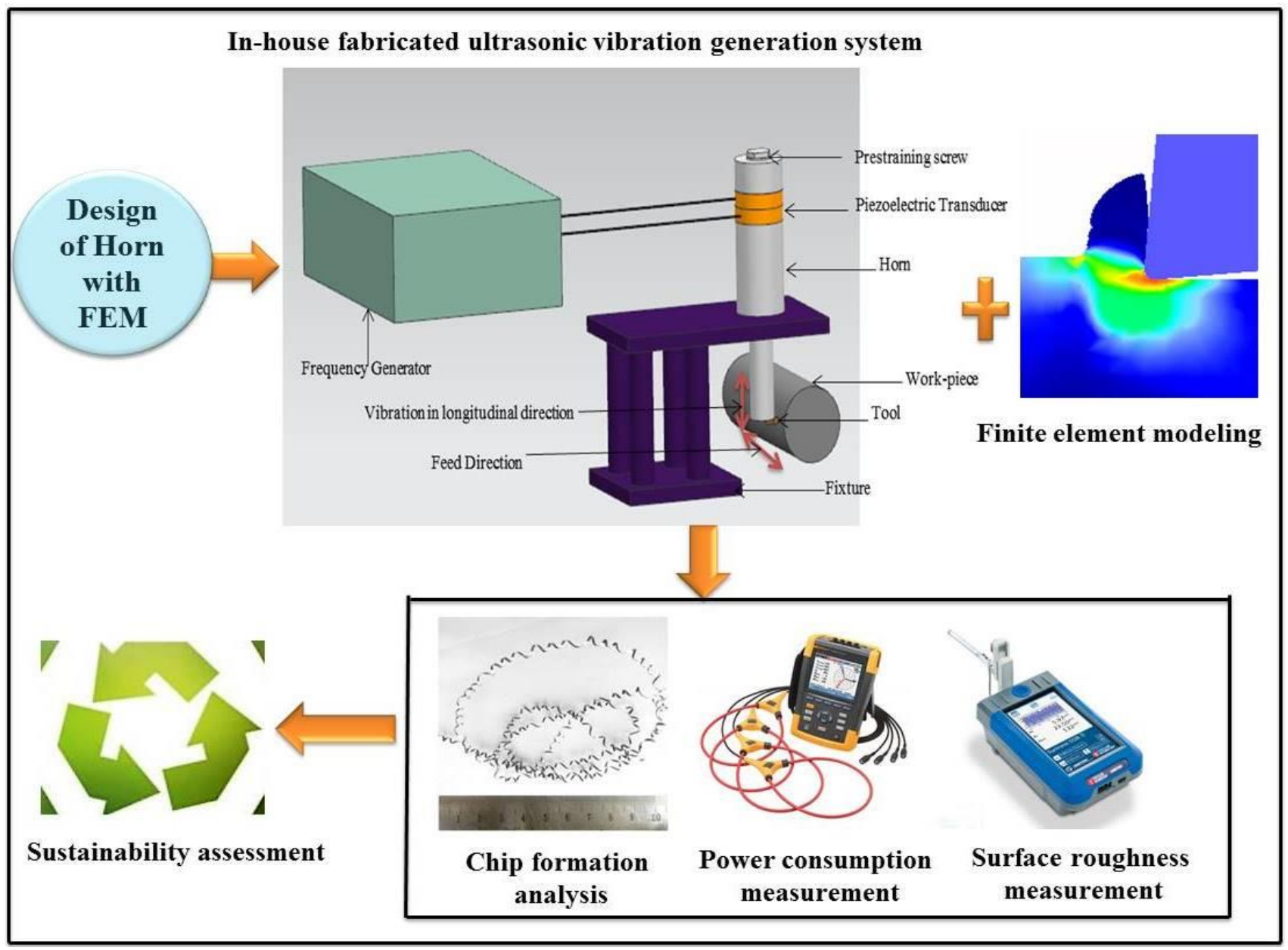

Fig.1 Complete experimental procedure of ultrasonic-assisted turning process and analysis

\subsection{Design of ultrasonic horn}

Horn is a waveguide for efficient transfer of ultrasonic energy from a source to a tool or load. It also transmits and amplifies the amplitude of the vibration between the input and output. Horns are of different types such as cylindrical horn, exponential horn, conical horn, hyperbolic horn, stepped horn, etc. The magnification factor of the steeped horn is the highest among all the other types of the horn [35]. The horn is a critical parameter as the vibration transmitted to the tool depends on the design, which is the length and diameter of the horn. If the length and diameter are not designed as per the criteria, the effect transverse vibration of the horn is taken place and the effect of the longitudinal vibration decreases. The equation of the wave through a solid medium is given by

$$
\frac{\partial^{2} p}{\partial x^{2}}=\frac{1}{c^{2}} \frac{\partial^{2} p}{\partial t^{2}}
$$

where $p$ is the wave, $x$ is length, $t$ is time and $c$ is the speed of sound through solid, which depends on the modulus of elasticity $(E)$ and density $(\rho)$ of the material $\left(c=\sqrt{\frac{E}{\rho}}\right)$. After the simplification of the wave equation, the Webster's horn equation (25) is given by 


$$
\frac{\partial^{2} p}{\partial x^{2}}+\frac{d}{d x}(\ln A) \frac{\partial p}{\partial x}+\frac{\omega^{2}}{c^{2}} p=0
$$

where $\omega$ is the frequency of the wave and A is the cross-section is of the solid bar. The stepped horn is of constant cross-section area as shown in Fig.2. For the stepped horn equation (2) is modified as follows:

$$
\frac{\partial^{2} p}{\partial x^{2}}+\frac{\omega^{2}}{c^{2}} p=0
$$

The solution of the equation (3) provides

$$
\omega_{n}=\frac{n \pi c}{l}
$$

where $n$ is for the mode shape of the given natural frequency for $n$ different eigenvalues. The length of the stepped horn has been calculated by using equation (4). In the present study, the length of the horn for the resonance frequency of $20 \mathrm{kHz}$ is $125 \mathrm{~mm}$. another important parameter of the horn is the amplification factor which is a ratio of input diameter $\left(D_{0}\right)$ to output diameter $\left(D_{1}\right)$.

$$
R_{m}=\left(\frac{D_{0}}{D_{l}}\right)^{2}
$$

In the present study, the horn used is of half wavelength. This is attributed to the node point (where the amplitude is zero) of the half-wavelength horn. The node point in the half-wavelength is at the middle, so it can be attached to the middle without any disturbance of wave propagation.

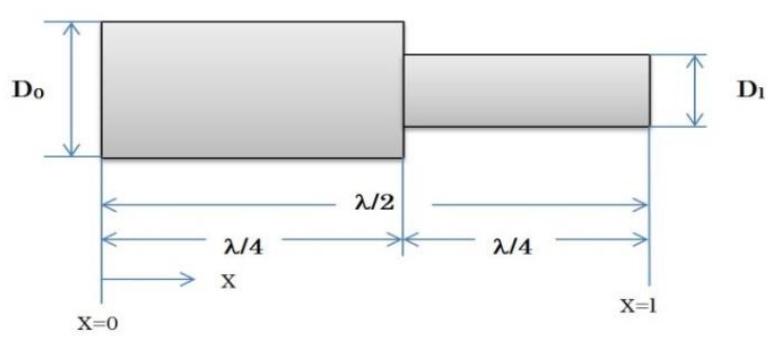

Fig. 2 Schematic of stepped horn

The analytical design of the stepped horn is verified with FEM (finite element modeling) design. The FEM design of the horn was carried out with Abaqus Explicit software to determine the natural frequency of the horn. In the FEM, the horn is discretized by a mesh of simple homogeneous elements connected by the number of nodes. The material used for the horn is mild steel with a density of $7.8 \mathrm{gm} / \mathrm{cc}$ and the modulus of elasticity was taken as $200 \mathrm{GPa}$ with 0.3 as Poisson's ratio. As a result, only the longitudinal mode of the vibration is considered. As the continuous system has infinite degrees of freedom, it gives $n$ number of solutions. The algebraic equations of the horn given $n$ different eigenvalues which are nothing but the $n$ different mode shapes [36]. From the given frequency, displacement, stress, and strain can be computed. The resonance frequency of the horn for the given material is $19675 \mathrm{~Hz}$ which would be due to some damping effect of the horn. 


\subsection{Workpiece material}

In this study, the forged bar of Nimonic 90 was used for experiments. Nimonic 90 is a precipitation-hardened nickel-base superalloy with high mechanical properties along with corrosion resistance. The material is strengthened by the addition of titanium and aluminum with $18-20 \%$ of chromium to enhance the corrosion resistance of the alloy. It is typically used for components subjected to extreme environments [37]. The chemical composition of the workpiece material is listed in Table 2.

Table 2 Chemical composition of Nimonic 90

\begin{tabular}{llllllllll}
\hline element & $\mathrm{C}$ & $\mathrm{Si}$ & $\mathrm{Mg}$ & $\mathrm{Cr}$ & $\mathrm{Ni}$ & $\mathrm{Ti}$ & $\mathrm{Al}$ & $\mathrm{Co}$ & $\mathrm{Fe}$ \\
\% weight & 0.08 & 0.13 & 0.018 & 18.1 & 58 & 2.4 & 1.09 & 18.5 & 0.82 \\
\hline
\end{tabular}

\subsection{Tool material}

For the turning experiments, $\mathrm{CVD}$ coated carbide inserts with a layer of $\mathrm{TiC}, \mathrm{Al}_{2} \mathrm{O}_{3}$, and $\mathrm{TiN}$ were used. The tool material had a tough micro-grain structure suitable for intermittent cutting. The specification of the cutting tool is provided in Table 3.

Table 3 Cutting tool specifications

\begin{tabular}{|c|c|}
\hline Insert part number & CNMG 120408CQ \\
\hline Rake angle & $5^{\circ}$ \\
\hline Relief angle & $0^{\circ}$ \\
\hline Nose radius & $0.8 \mathrm{~mm}$ \\
\hline Lead angle & $45^{\circ}$ \\
\hline Point angle & $80^{\circ}$ \\
\hline
\end{tabular}

\subsection{Experimental methodology}

An experimental methodology was decided by the combination of process parameters such as cutting speed $(V)$, feed rate $(f)$, depth of cut $(D O C)$ and frequency $(F)$ as shown in Table 4. UAT is constrained by the critical cutting velocity above which the tool separation with the work-piece vanishes. The relation between critical cutting velocity $\left(V_{c}\right)$ and the cutting velocity $(V)$ is provided in equation (6) in which $a$ is amplitude, $D$ the diameter of work-piece, and $N$ is rpm of spindle [38]. The UAT was developed for the resonance frequency of $20 \mathrm{kHz}$. Based on the resonance frequency and amplitude, the critical cutting velocity which permits the maximum cutting velocity $(V)$ is $75.36 \mathrm{~m} / \mathrm{min}$. In this study, all the process parameters were selected based on the previous literature of UAT $[11,13,14,15,16]$. Here, experiments were performed based on three levels of cutting speed feed rate, depth-of-cut and vibration frequencies.

$$
V_{c}=2 \pi a F>V=\pi D N
$$

For all experiments, the length of cut was approximately $50 \mathrm{~mm}$. A total of 81 experiments were conducted. Each experimental run was repeated 3 times for consistency. The average surface roughness $\left(R_{a}\right)$ and power 
consumption $(P)$ were measured after each experiment. A Taylor Hobson surface roughness tester (Fig.1) was used to measure the average surface roughness $\left(R_{a}\right)$. Power consumption $(P)$ was measured with a power analyzer (Fig.1).

Table 4 Levels of process parameters

\begin{tabular}{|c|c|c|c|}
\hline Parameters & \multicolumn{3}{|c|}{ Range } \\
\hline & Level 1 & Level 2 & Level 3 \\
\hline Cutting speed $(\mathrm{m} / \mathrm{min})$ & 27.1 & 40.7 & 61.1 \\
\hline Feed $(\mathrm{mm} / \mathrm{rev})$ & 0.11 & 0.22 & 0.33 \\
\hline Depth-of-cut $(\mathrm{mm})$ & 0.1 & 0.2 & 0.3 \\
\hline Frequency $(\mathrm{kHz})$ & 20 & 18 & 0 (conventional) \\
\hline Amplitude $(\mu \mathrm{m})$ & & 10 & \\
\hline
\end{tabular}

\subsection{Physical interpretation of process mechanism}

The UAT is differed by the CT in the repeating action of the cutting tool attached to the horn. The repeating action of engagement and disengagement of the insert with the work-piece is shown in Fig.3 (a) and (b) respectively. The physical interpretation of the process is given in Fig.3(c) in which $T$ is the cycle time and $t_{c}$ is cutting time.

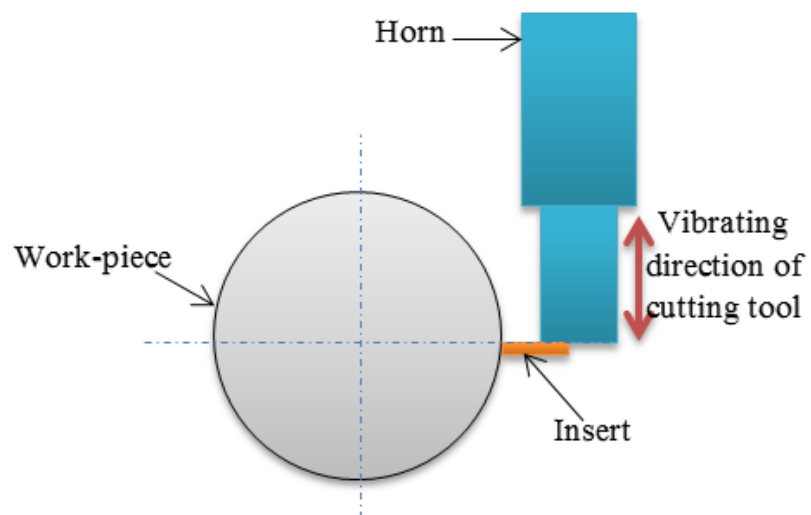

(a)

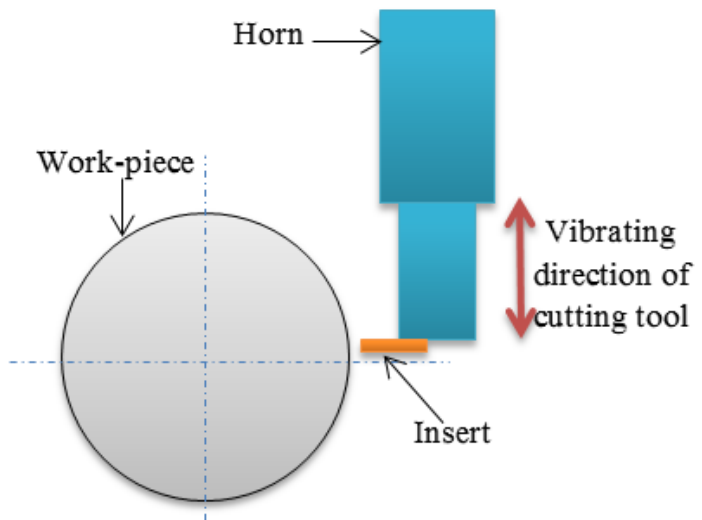

(b)

Fig.3 (a) Insert engagement with the work-piece and (b) disengagement with the work-piece (not to scale) 


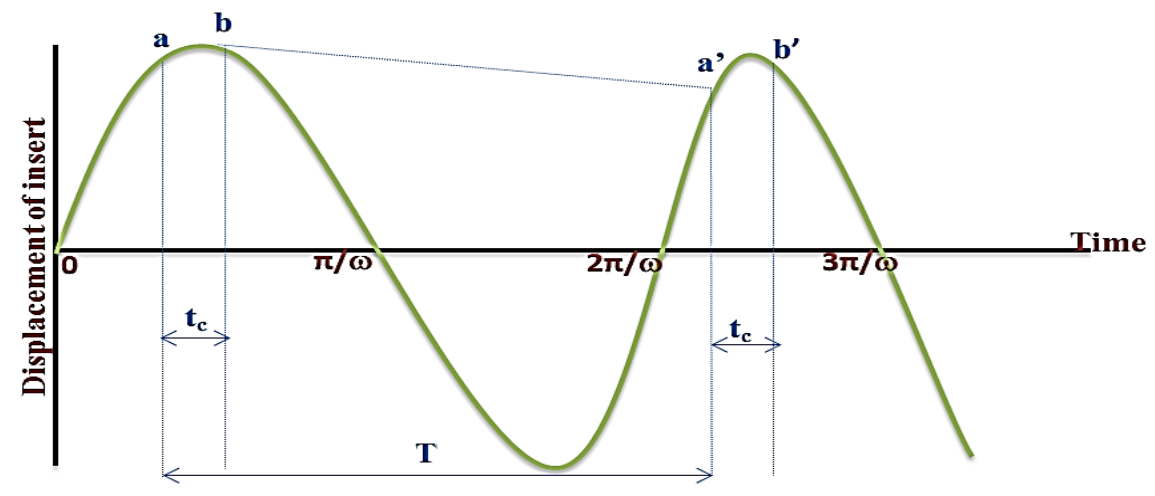

Fig.3(c) Displacement of the insert with the time varies in a sinusoidal manner

It can be seen from Fig. 3(c) that the sinusoidal cutting action of insert takes place in UAT. The insert comes in the contact with the work-piece at point $a$, and remains the engage with the work-piece for $t_{c}$ time and disengage at the point $b$. The insert remains ideal or disengages with the work-piece till the next cycle will be started. The cycle repeats from the point $a^{\prime}$ when the insert again comes in the contact with the workpiece. The repetitive cutting action of the UAT gives a significant improvement in the output responses. However, the UAT is highly affected by the amplitude, resonance frequency at which the horn is designed rigidity of the fixture, etc. In the developed UAT set up the system was tuned at the resonance frequency of $20 \mathrm{kHz}$ and was also verified with the oscilloscope.

\subsection{Finite element modeling of the UAT process}

A 2D finite element modeling of the UAT process was developed using DEFORM finite element tool. The cutting tool was of tungsten carbide and work-piece was of Nimonic 90 were developed and Tool was assumed to be rigid. The geometry of the tool was taken the same as in experimental work. For the UAT process, $20 \mathrm{kHz}$ vibration was given to the tool with 10-micron amplitude in the cutting velocity direction. In the model, the work-peace moves with a constant velocity which corresponds to $V=27.14 \mathrm{~m} / \mathrm{min}$. The cutting tool vibrates harmonically in the cutting velocity direction is given by equation (7) [25].

$$
V_{x}=a \cos \omega t \text { And } V_{y}=0
$$

where $V_{x}$ and $V_{y}$ are the velocity in $x$ and $y$ direction respectively. $\omega$ is angular frequency $=20 \mathrm{KHz}, a$ is the amplitude $=10$ microns, $t$ is the time.

The cutting tool vibrating velocity is $a \omega \sin \omega t$ should be greater than $V_{c}$ to separate the tool from the workpiece during the UAT process.

\section{Results and discussion}

In this section, a comparative study between UAT and CT processes and machinability aspects such as surface roughness, power consumption, and chip formation are discussed.

\subsection{Variation in average surface roughness $\left(R_{a}\right)$ with cutting speed}

The variation in $R_{a}$ with cutting speed for constant depth-of-cut and feed rate is shown in Fig. 4 . It can be seen that the minimum value of $R_{a}$ at $27.1 \mathrm{~m} / \mathrm{min}$ is $0.3 \mu \mathrm{m}$ for UAT at $20 \mathrm{kHz}$ and $1.5 \mu \mathrm{m}$ for CT which 
implies that an $80 \%$ reduction in $R_{a}$ can be achieved with UAT. However, the reduction decreases with an increase in cutting speed. As the cutting speed increases, the $R_{a}$ for CT decreases whereas no significant change in UAT was observed.

In the CT, the TWCR (ratio of contact of the tool with work-piece to the total contact of the tool with workpiece) is $100 \%$ whereas, in the UAT, it is less (i.e. due to tool-separation in every vibratory cycle). The intermittent cutting action reduces the cutting force with no built-up edge formation on the machined surface. In the UAT, as the cutting speed increases, $R_{a}$ increases slightly, due to an increase in the TWCR [26]. In the CT, at a lower cutting speed built-up edge produces rough surface [39] but as the cutting speed increases, the $R_{a}$ decreases because at higher cutting speeds the size of the built-up edge decreases due to the insufficient time for welding of micro-particles of the work-piece with the cutting tool [40].

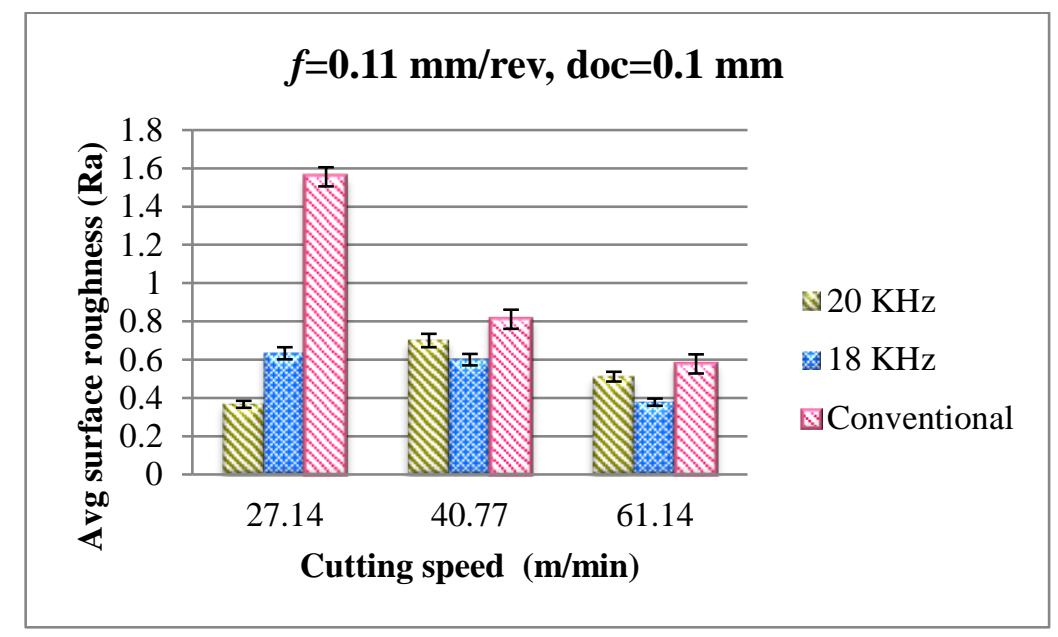

Fig.4 Variation in Average surface roughness $\left(R_{a}\right)$ with cutting speed

\subsection{Variation in average surface roughness $\left(R_{a}\right)$ with vibration frequency}

In the UAT, as the frequency increases the tool vibration timing decreases as shown in Fig. 5. It can be seen that the tool vibration timing for the higher frequency $T_{1}$ is lower than the tool vibration timing for lower frequency $T_{2}$, as a result, the tool work-piece contact ratio for higher frequency $\left(t c_{1}\right)$ is lower than that for lower frequency $\left(t c_{2}\right)$. Therefore, the tool cutting area experiences a shorter duration of pulsating cutting force at a higher frequency. Thus, by increasing the tool vibration frequency, an improvement in cutting quality and surface finish may be expected [26]. From Fig. 5, it can be seen that there is no significant difference in $R_{a}$ for a frequency of $20 \mathrm{kHz}$ and $18 \mathrm{kHz}$. The $R_{a}$ value for $20 \mathrm{kHz}$ is $0.3 \mu \mathrm{m}$ and for $18 \mathrm{kHz}$ is $0.5 \mu \mathrm{m}$ for all values of cutting speed. 


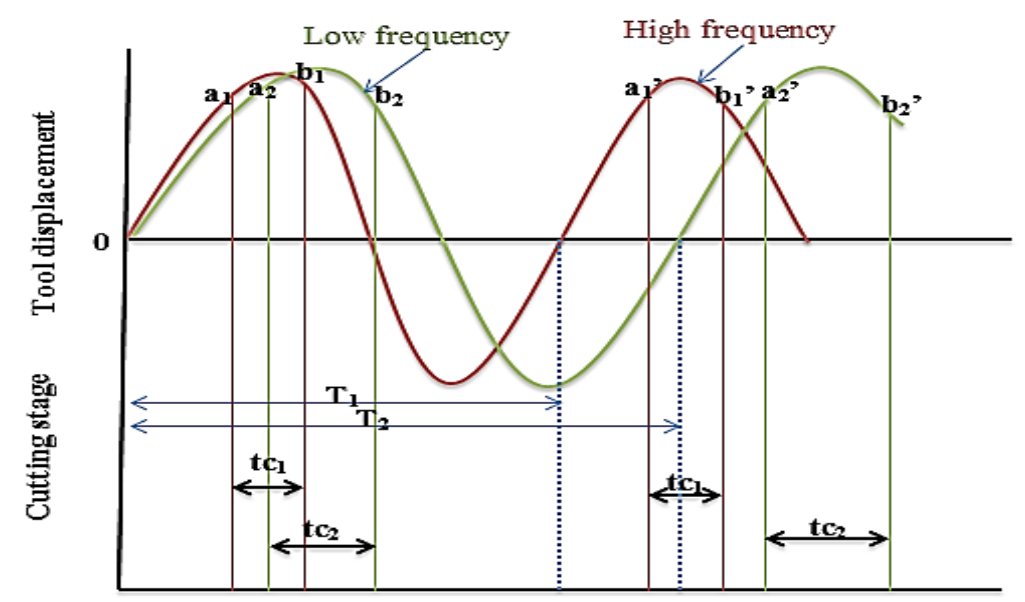

Fig.5 Tool displacement for two different frequencies

\subsection{Variation in average surface roughness $\left(R_{a}\right)$ with feed rate}

The variation in $R_{a}$ with feed rate for constant DOC and cutting speed is shown in Fig. 6. It can be observed that the minimum value of $R_{a}$ is $0.3 \mu \mathrm{m}$ in UAT at $20 \mathrm{kHz}$, whereas $1.5 \mu \mathrm{m}$ in the CT for the feed rate of $0.11 \mathrm{~mm} / \mathrm{rev}$ (i.e. $80 \%$ reduction in $R_{a}$ in UAT). This result was also observed at the higher value of feed rate. The result shows significant improvement in $R_{a}$ at the resonance frequency $20 \mathrm{kHz}$, whereas, at 18 $\mathrm{kHz}$, it does not show linear variation as the UAT does not provide the effective vibration other than the resonance frequency. Still, the value of $R_{a}$ is lower for the feed rate of $0.11 \mathrm{~mm} / \mathrm{rev}$ and $0.33 \mathrm{~mm} / \mathrm{rev}$ and does not much differ for the feed rate of $0.22 \mathrm{~mm} / \mathrm{rev}$.

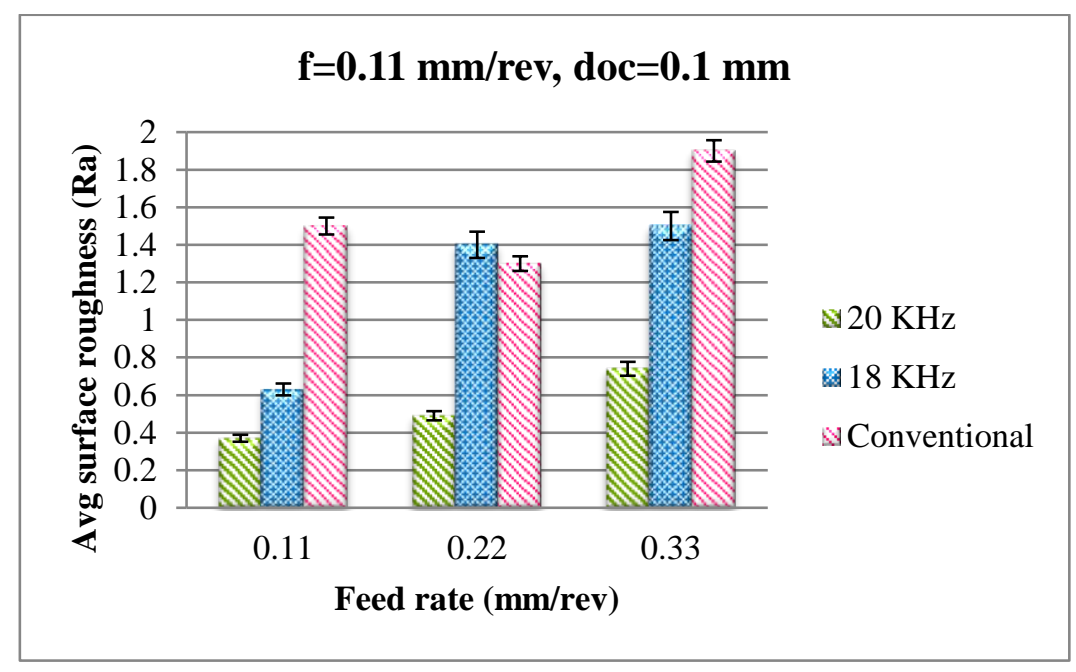

Fig.6 Variation in Average surface roughness $\left(R_{a}\right)$ with feed rate

The $R_{a}$ value decreases as the feed rate increases due to spanzipfel effect up to some threshold value of the feed rate but again it starts increasing as the feed rate increases [41]. The spanzipfel effect plays a role at a very low feed rate but in the present research, the feed rate is not much lower. Secondly, The empirical relation of $R_{a}$ with feed rate is given by equation (7) in which, the $R_{a}$ is directly proportional to the square of the feed rate. In the UAT and CT processes, as $R_{a}$ increases the feed rate increases. 


$$
R_{a}=\frac{f^{2}}{8 r}
$$

where $r$ is the nose radius in mm. In the UAT, as the tool repeatedly disengaged from the work-piece, relatively lower heat is generated in the cutting zone due to less friction. Hence, the value of $R_{a}$ is less in the UAT as compared to that of CT.

\subsection{Variation in average surface roughness $\left(R_{a}\right)$ with depth-of-cut}

The variation in $R_{a}$ with depth-of-cut for constant feed rate and cutting speed is shown in Fig.7. It can be observed that for the $0.1 \mathrm{~mm}$ depth of cut, the $R_{a}$ is $0.4 \mu \mathrm{m}$ in UAT at $20 \mathrm{kHz}$ and $1.6 \mu \mathrm{m}$ in CT. It shows about $75 \%$ reduction in $R_{a}$ in UAT as compared to CT. For the $0.3 \mathrm{~mm} \mathrm{DOC.,} \mathrm{the} R_{a}$ is $0.8 \mu \mathrm{m}$ in UAT and $2.0 \mu \mathrm{m}$ in CT that is a $60 \%$ reduction in $R_{a}$ in UAT.

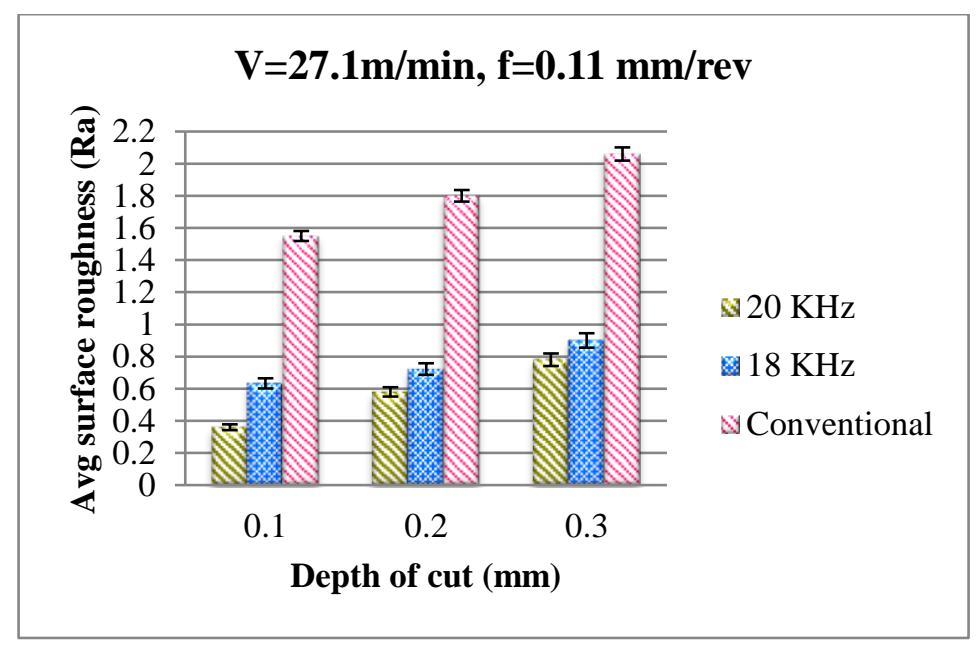

Fig.7 Variation in Average surface roughness $\left(R_{a}\right)$ with depth of cut

In the CT, as the DOC. increases, more tool area comes in the contact with the work-piece, and therefore more frictional heat is generated. Due to the low thermal conductivity of Nimonic 90 , the heat is accumulated at the cutting zone and that leads to an increase in temperature. At high-temperature, Nimonic 90 has a higher affinity to tool materials resulting in welding of the micro-particles of the work-piece to the cutting tool resulting in the poor surface finish [42]. In the UAT, because of the intermittent cutting action, the tool repeatedly separates from the work-piece and relatively less heat was generates during the engagement of the tool which, results in a lower value of $R_{a}$.

\subsection{Power consumption $(P)$}

Power consumption is a prominent aspect during turning of hard materials. Theoretically, total Power consumption $\left(P_{t}\right)$ is a sum of ideal power $\left(P_{0}\right)$ and power consumed during machining $(P)$ which is given by equation $(8)$. The ideal power $\left(P_{0}\right)$ includes power required for running coolant pump, other idling equipments etc. In the present work, only power consumed during machining is considered for analysis.

$$
P_{t}=P_{0}+P
$$


The power consumed during machining is multiplication of cutting force and cutting speed which is given by equation (9) [43].

$$
P=\frac{F_{c} * V}{60}
$$

In which, $F_{c}$ is main cutting force in Newton and $V$ is the cutting speed in $\mathrm{m} / \mathrm{min}$ which depends on RPM of the spindle according to equation (10).

$$
V=\pi D N
$$

In which, $D$ is diameter of work-piece in $\mathrm{m}$ and $N$ is RPM of spindle.

The modified power consumption $\left(P_{m}\right)$ model is given by equation (11) [44],

$$
P_{m}=k * M R R
$$

In which $k$ is material constant which depends on the physical characteristic of machining process, MRR is material removal rate in $\mathrm{mm}^{3} / \mathrm{s}$.

MRR is given by

$$
M R R=\frac{V^{*} f^{*} D O C}{60}
$$

Where, DOC is depth of cut in $\mathrm{mm}$ and $f$ is feed rate in $\mathrm{mm} / \mathrm{rev}$.

The influence of cutting parameters on the power consumption during machining $(P)$ is described in following sub-sections.

\subsubsection{Variation in power consumption $(P)$ with cutting speed}

The variation in $P$ with cutting speed for constant DOC and feed rate is shown in Fig 8 . The $P$ was $280 \mathrm{~W}$ in UAT at $20 \mathrm{kHz}$ and was $320 \mathrm{~W}$ in CT process for $27.1 \mathrm{~m} / \mathrm{min}$, which represents $12-13 \%$ lower in case of UAT. The reduction in $P$ was only for the process which is carried out at resonance frequency (20 kHz). The behavior of the $P$ for the $18 \mathrm{kHz}$ was un-even as shown in Fig 8 . The $P$ for $20 \mathrm{kHz}$ was 280 W whereas for the $18 \mathrm{kHz}$ was $320 \mathrm{~W}$ for $V=27.1 \mathrm{~m} / \mathrm{min}, f=0.11 \mathrm{~mm} / \mathrm{rev}$, and $0.1 \mathrm{~mm} \mathrm{DOC}$. At the cutting speed of $61.1 \mathrm{~m} / \mathrm{min}$, the $P$ was $350 \mathrm{~W}$ for $18 \mathrm{kHz}$ and $290 \mathrm{~W}$ for $20 \mathrm{kHz}$. 


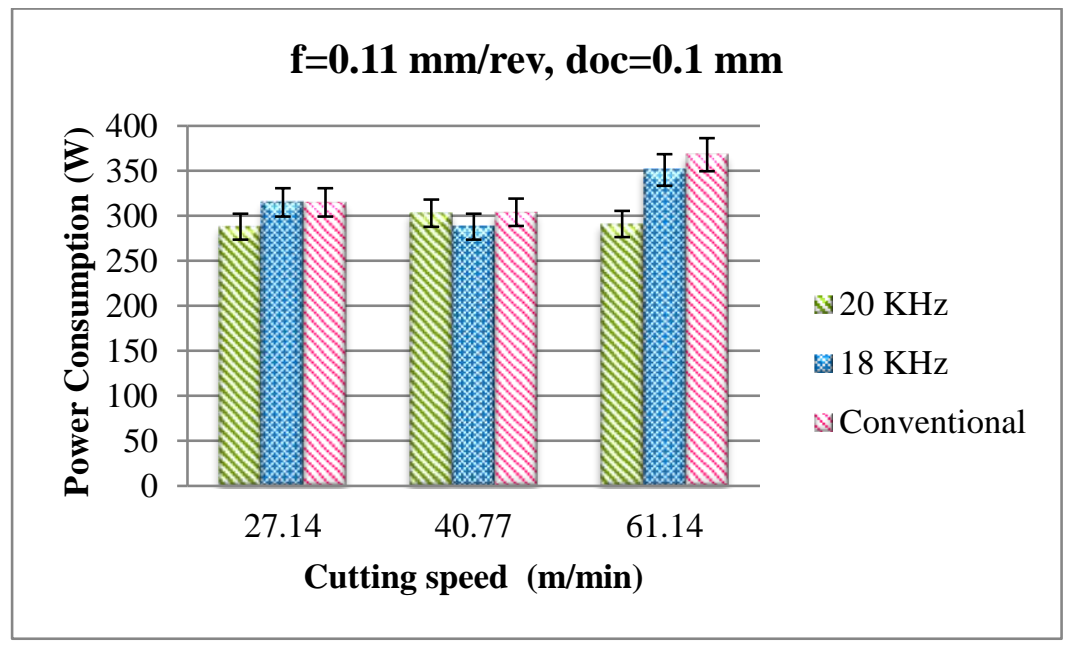

Fig.8 Variation in power consumption $(P)$ with cutting speed

The power consumption was mainly dependent on the RPM of the spindle and cutting time according to equation (9) and (10). As the cutting speed increased, RPM of the spindle also increased which consumed more power from the motor. Moreover, at the higher cutting speed, MRR is also high which forces the system to spend more power. The heat at the tool-work piece interface increases with the cutting speed and due to this, the material becomes hardened. Eventually, due to the micro-hard carbide particles, the energy requires increases in the CT process [45].

\subsubsection{Variation in power consumption $(P)$ with feed rate}

The variation in $P$ with feed rate for constant cutting speed and depth-of-cut is shown in Fig. 9 . The $P$ is 280 $\mathrm{W}$ in UAT at $20 \mathrm{kHz}$ and is $330 \mathrm{~W}$ in CT for $0.11 \mathrm{~mm} / \mathrm{rev}$. That is around $12-13 \%$ lower value of $P$ in UAT as compared to CT. At feed of $0.33 \mathrm{~mm} / \mathrm{rev}, P$ is $270 \mathrm{~W}$ in UAT at $20 \mathrm{kHz}$ and was $290 \mathrm{~W}$ in CT, with a reduction of $6 \%$ in the UAT. It can be seen that the $P$ is slightly higher for the $18 \mathrm{kHz}$ frequency as compared to $20 \mathrm{kHz}$ frequency. The $P$ is $280 \mathrm{~W}$ for $20 \mathrm{kHz}$ and is $320 \mathrm{~W}$ for $18 \mathrm{kHz}$. As the feed rate increases, the machining time to cut the length decreases, hence the tool is engaged with the work-piece for less time period at a higher feed rate when compared to lower feed rate. This leads to a reduction in power consumption at higher feed rates. On the other hand, $P$ increases as the MRR increases according to equation (12) which leads to increase in $P$. Ultimately, it can be noted that the variation of $P$ with feed rate is not significant due to the simultaneous effects of the above mentioned two parameters. 


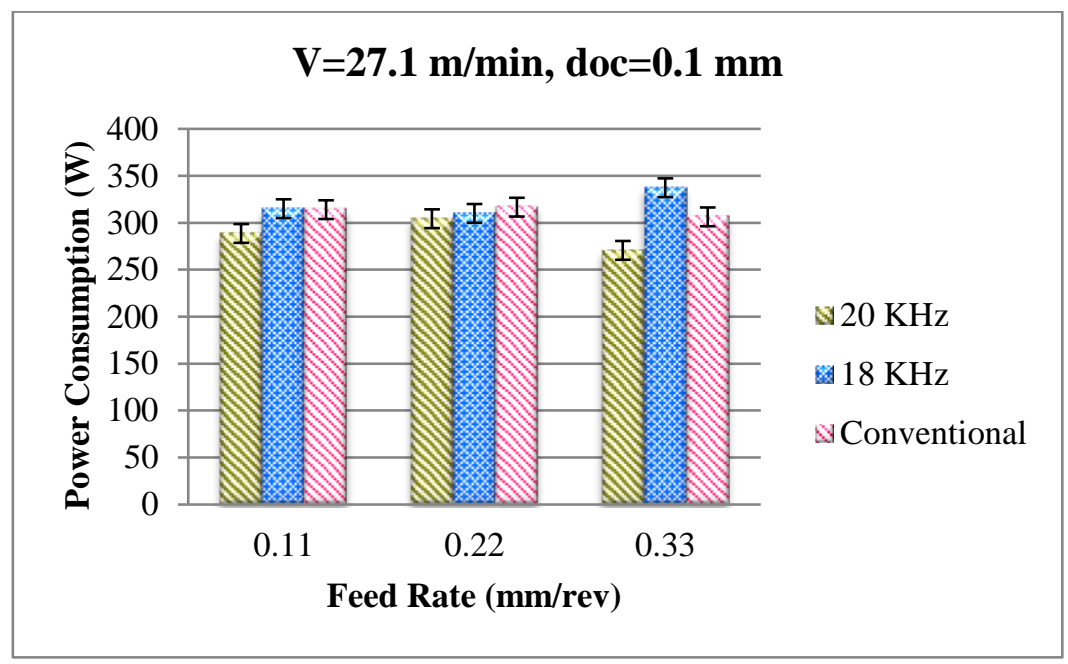

Fig.9 Variation in power consumption $(P)$ with feed rate

\subsubsection{Variation in power consumption $(P)$ with depth-of-cut}

The variation in $P$ with depth-of-cut for constant cutting speed and feed rate is shown in Fig 10 . The $P$ is around $280 \mathrm{~W}$ for UAT at $20 \mathrm{kHz}$ and is $320 \mathrm{~W}$ for CT at $0.1 \mathrm{~mm}$ DOC., $0.11 \mathrm{~mm} / \mathrm{rev}$ feed and $27.1 \mathrm{~m} / \mathrm{min}$ cutting speed. That is around $12-13 \%$ lesser $P$ in UAT than that of CT process. The $P$ is slightly decreased as the DOC increased in both of the processes. For $0.3 \mathrm{~mm}$ depth of cut, $P$ is $270 \mathrm{~W}$ at $20 \mathrm{kHz}$ for UAT and is $290 \mathrm{~W}$ for CT process that is around 6-7\% reduction in power consumption in UAT process. For the 18 $\mathrm{kHz}$ frequency, the variation in $P$ is different. The $P$ is around $320 \mathrm{~W}$ for $0.1 \mathrm{~mm}$ DOC and is $370 \mathrm{~W}$ for 0.3 $\mathrm{mm}$ DOC for UAT at $18 \mathrm{kHz}$. As the DOC increases, tool penetrates more in work-piece and it also increases MRR according to equation (12), and ultimately it results in more power consumption $(P)$.

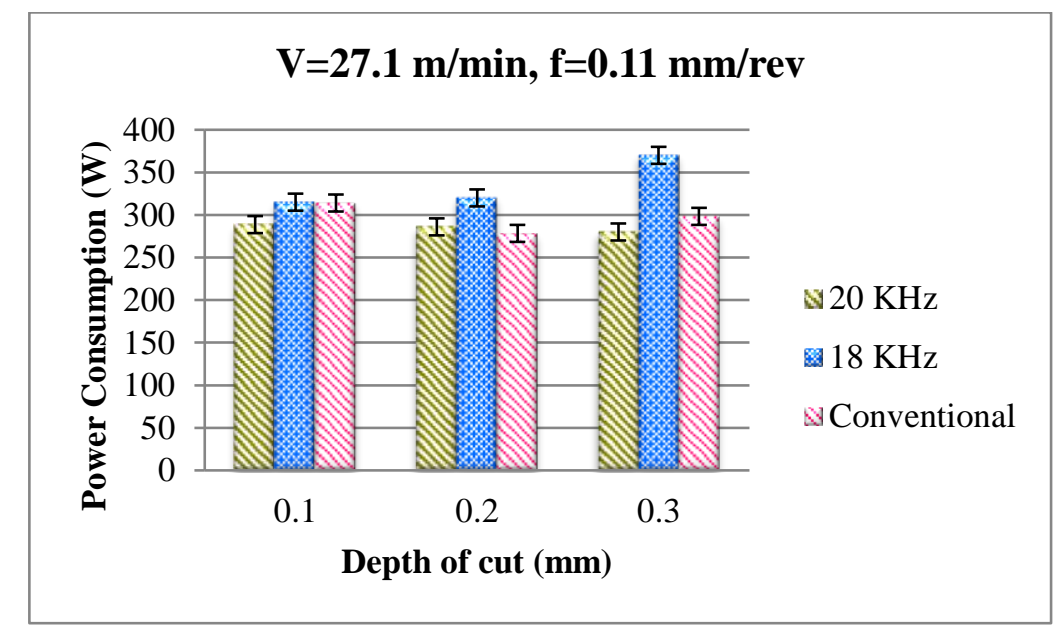

Fig.10 Variation in power consumption $(P)$ with depth of cut

\subsection{Chip formation analysis in UAT and CT processes}

Chip analysis in metal cutting forms an integral part of machinability studies. Various physical phenomena such as a rise in temperature during machining, cutting forces, material composition and are 
closely interrelated with chip formation studies [42]. The friction in the cutting process influences the machined surface. The chips formed during the machining of Nimonic 90 carried out with UAT ( $20 \mathrm{kHz}$ and $18 \mathrm{kHz}$ ) and CT as shown in Fig 11(a).

It can be seen from Fig. 11(b) that the chips produced in UAT are smooth, thinner and shorter when compared to CT. As discussed earlier that in the CT continuous contact between tool and work-piece experiences a longer timing of surface contact with chip, which results in higher temperatures and friction producing thicker chips in CT [26]. These kinds of chips have an adverse effect on the cutting area leading to large cutting forces. Moreover, in CT, longer chips are undesirable which leads to an entanglement of chips with the cutting tool and produces the rough surface [5]. In UAT, repeated separation of tool and work-piece reduces the friction between tool and chip when the tool friction decreases there is a corresponding increase in shear angle and an ultimately decrease in the chip thickness. Similar results are also shown in [46]. Moreover, this smooth and short chips produced in UAT do not stick to the work-piece material and hence reduced the surface roughness value. Further, because of the smoother and shorter chips directly related to the shear angle and in the case of UAT it is increased. This increase in the shear angle resulted in decrease in the chip thickness and good surface finish is produced with increasing frequency of vibration.

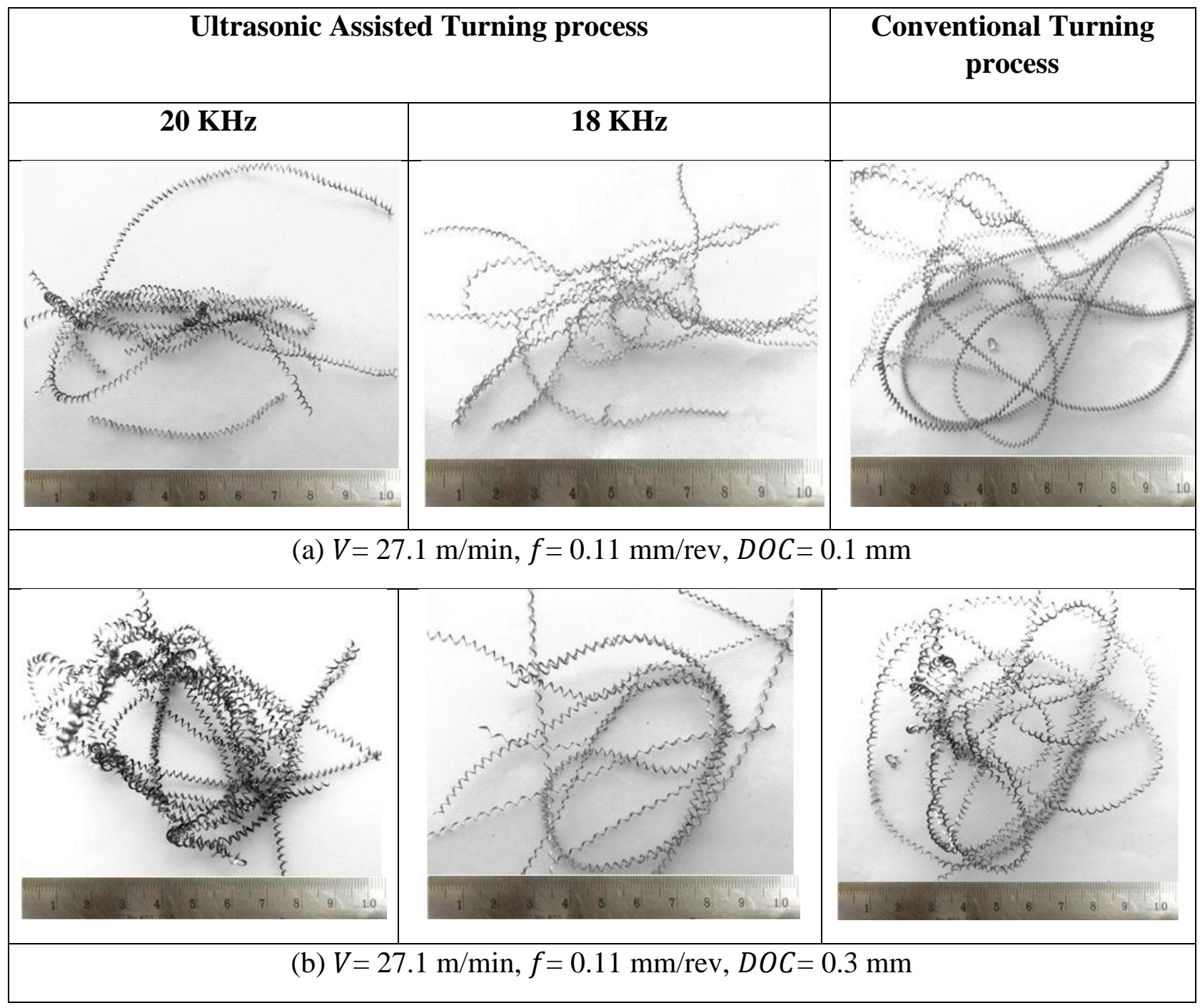




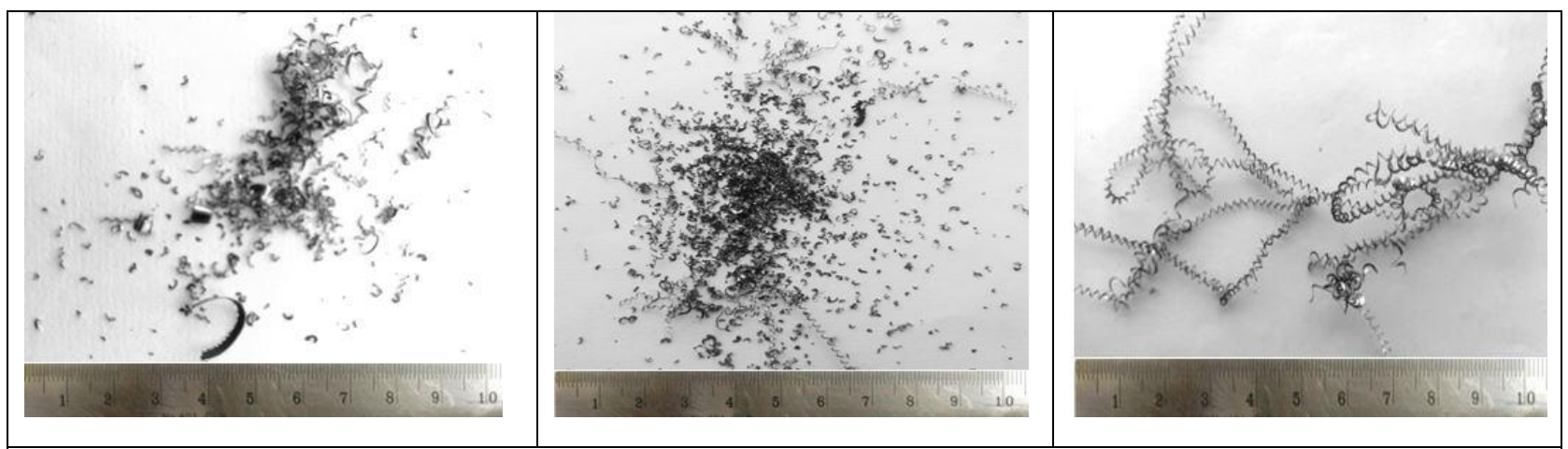

(d) $V=61.1 \mathrm{~m} / \mathrm{min}, f=0.11 \mathrm{~mm} / \mathrm{rev}, D O C=0.1 \mathrm{~mm}$

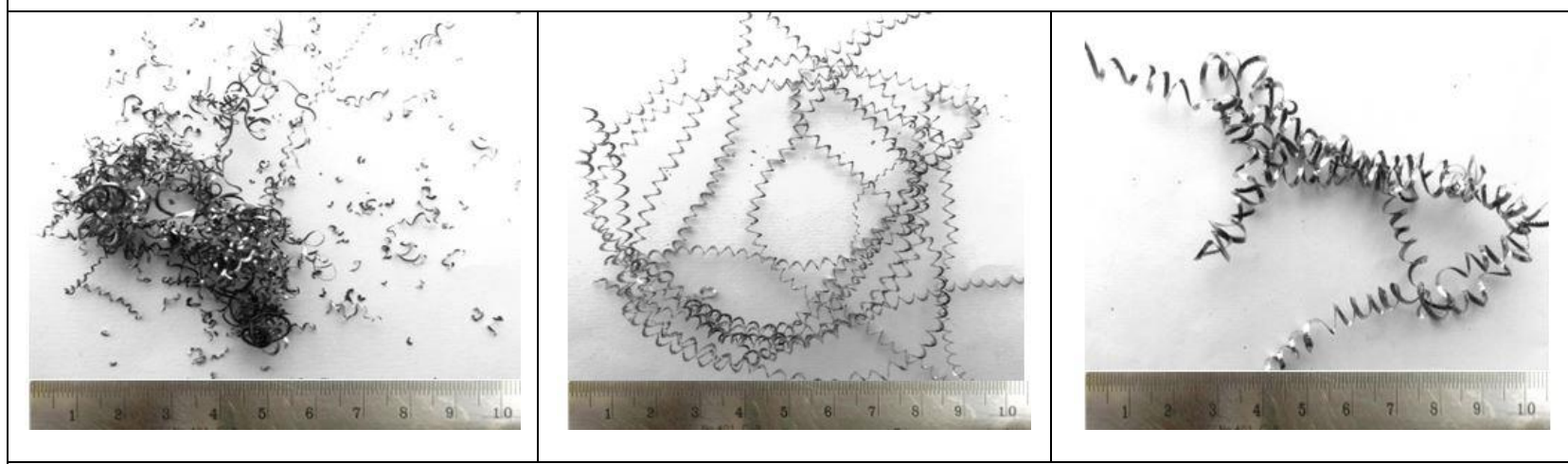

(e) $V=61.1 \mathrm{~m} / \mathrm{min}, f=0.11 \mathrm{~mm} / \mathrm{rev}, D O C=0.3 \mathrm{~mm}$

Fig.11 (a) Chip formed during UAT and CT processes

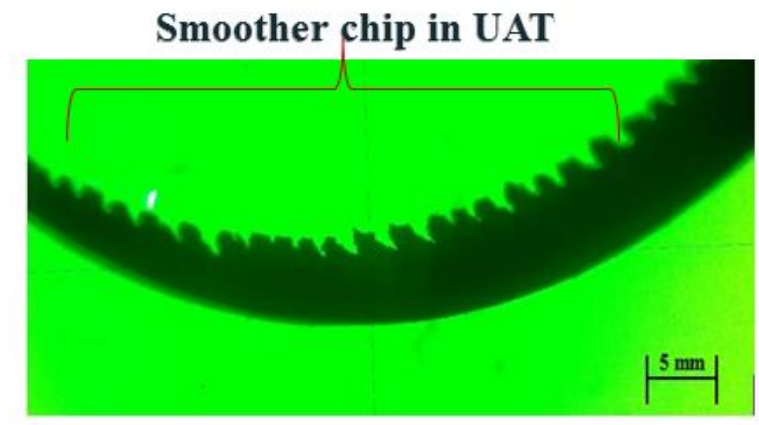

(a)

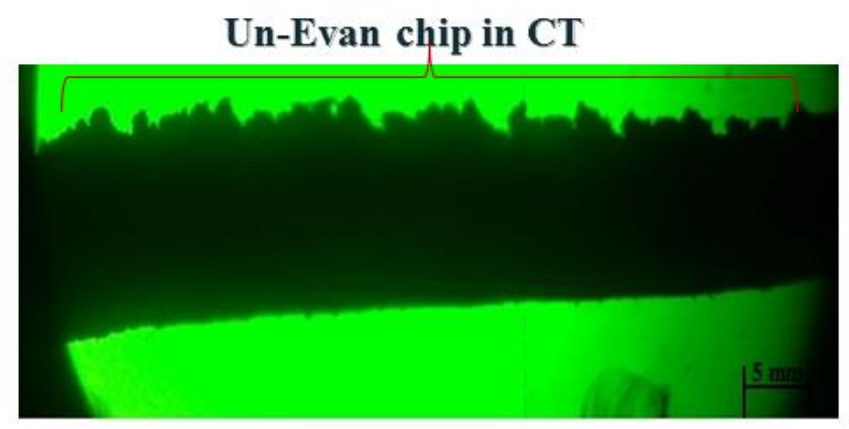

(b)

Fig. 11(b) Chips smoothness and Unevenness during UAT and CT processes

\subsection{FE modeling results of processes}

The results obtained from the simulation of $\mathrm{CT}$ and UAT processes are described here. The UAT process could be divided basically into four cycles as shown in Fig. 12a-d. It is showed in Fig. 12(a) that tool first comes with the work-piece and then it starts to penetrate in the work-piece (Fig.12 (b)). Once it fully penetrates in the work-piece (Fig.12 (c)) then it starts to disengage with the work-piece as shown in Fig. 12(d) and it completes one cycle. The stress distribution during the UAT and CT process is shown in Fig. 12 and in Fig. 13 respectively. During the first stage of the cycle, the stress induces is approximately $500 \mathrm{MPa}$. During the second stage, when a tool comes in the contact with work-piece, the effective stress goes up to approximately $1500 \mathrm{MPa}$. During the third stage, when the tool fully penetrates into work-piece, the stress 
reaches approximately $1660 \mathrm{MPa}$. During the last stage, when the tool disengages with work-piece, the effective stress again decreases. It can be said that the maximum effective stress induces during the CT and UAT processes are almost the same which is approximately equal to $1660 \mathrm{MPa}$. The stress distribution during the UAT process is quasistatic as it fluctuates during the cycle of the process [47]. This quasi-static nature of the stress distribution also shows the intermittent nature of the UAT process. Hence, the mean stress generated during the UAT process is significantly lower than that generates during the CT process. This could attribute to the reduction in the cutting force and power consumption during UAT process. Moreover, the effective strain induces during the CT process is $8.39 \mathrm{~mm} / \mathrm{mm}$ whereas, during the UAT process, it is $7.90 \mathrm{~mm} / \mathrm{mm}$ which is around $7.45 \%$ reduction in effective strain in the UAT process.

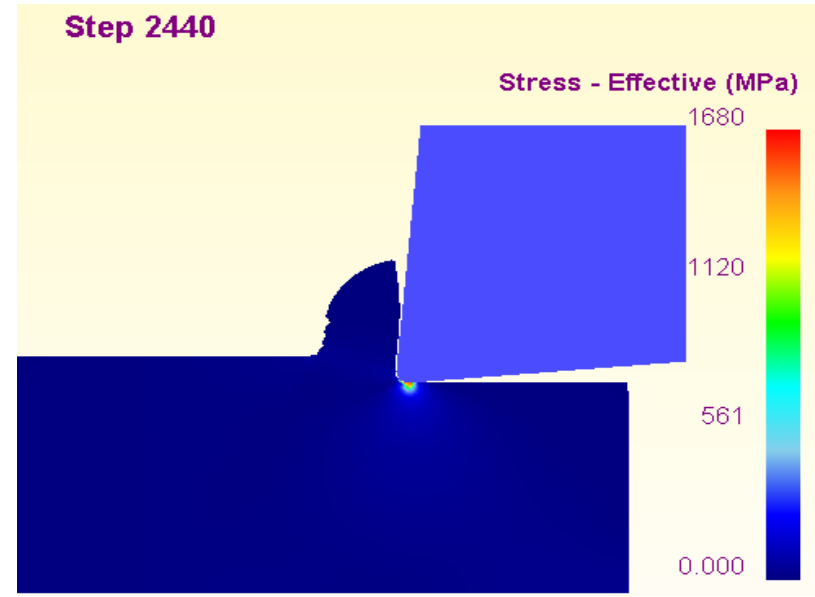

(a)

Step 2490

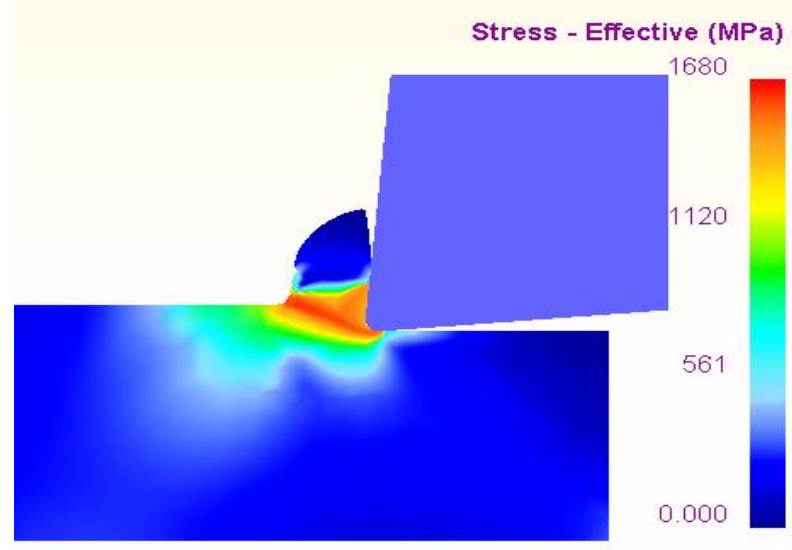

(c)

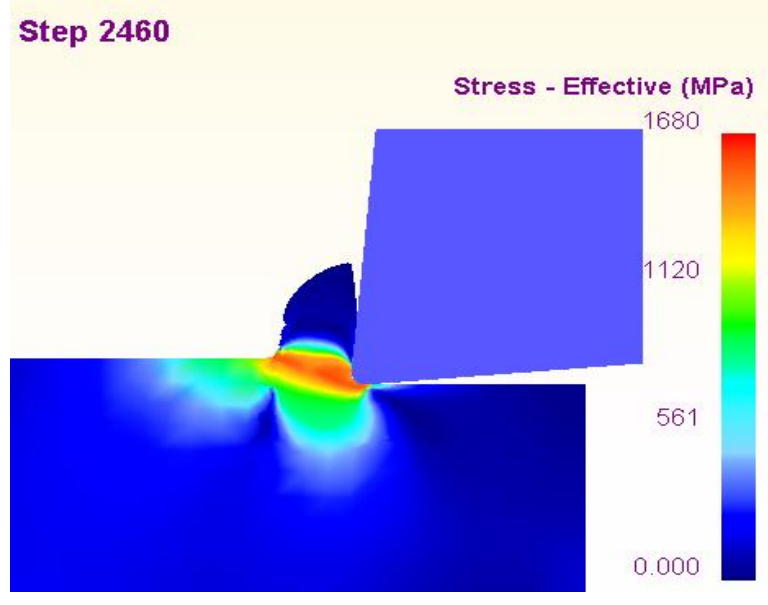

(b)

Step 2510

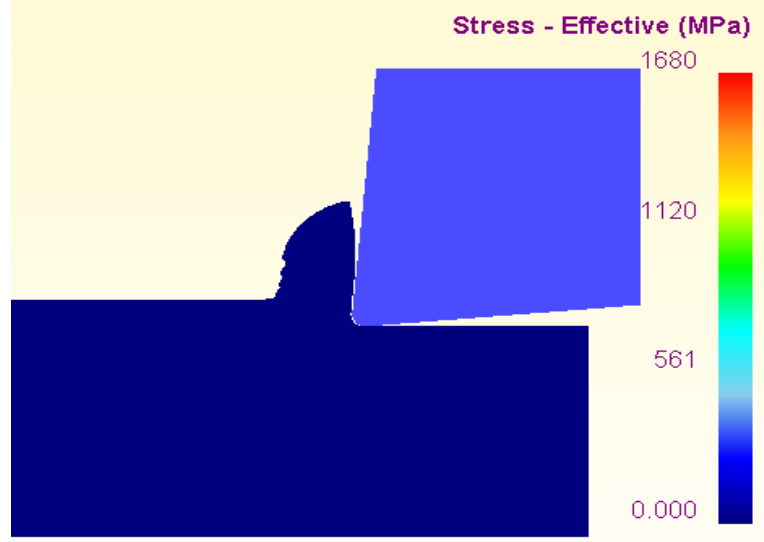

(d)

Fig. 12 Steps during the simulation of UAT (a) tool approaches for engagement with work-piece (b) tool starts to penetrate in work-piece (c) tool fully penetrates in work-piece (d) Tool disengages with the workpiece 


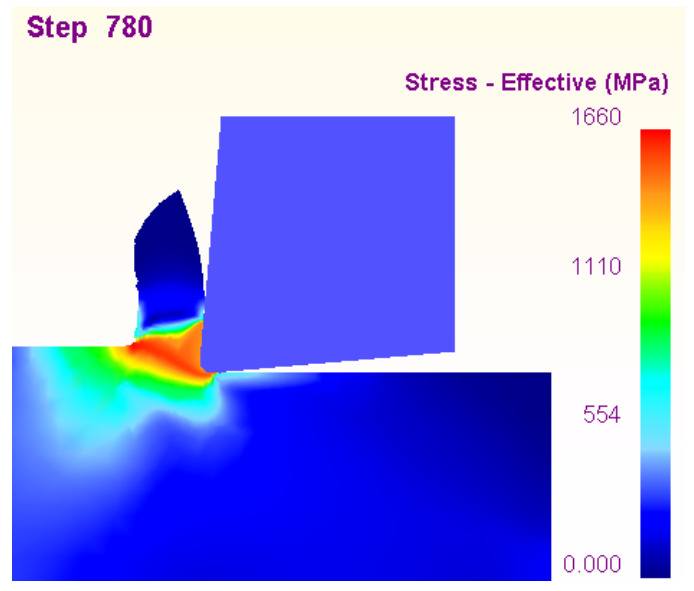

Fig. 13 Simulation without vibration (CT)

\section{Sustainability assessment}

It is essential to consider the sustainability aspects during machining processes to achieve optimal and sustainable cutting conditions. The sustainability assessment model of Hegab et al. [48] proposed a general assessment model to obtain the optimal design variables levels (i.e. based on both turning responses and sustainability performance), and this model was implemented in the current study. The predicted/optimal values consider the machining outputs (i.e., $R_{a}$ and $P$ ) as well as the performance indicators of the main sustainability pillars such as environmental impact, machining costs, and safety-health aspects. In this study, Ene is the environmental performance indicator which shows the carbon dioxide emissions according to the power consumed in each experiment using a standard defined emission intensity [49]. Regarding the personal health and operation safety, the selected sustainable indicators are the high-speed surface exposure (OS hss $_{\text {) }}$ and safety indicator (OSs), which are lower-the-better indicators. $\mathrm{OS}_{\mathrm{hss}}$ values have been set as "1" at cutting speeds of $27.1 \mathrm{~m} / \mathrm{min}$, "2" for $40.7 \mathrm{~m} / \mathrm{min}$, and "3" at cutting speed of $61.1 \mathrm{~m} / \mathrm{min}$. In this work, equallyweighting factors are employed for all sustainable indicators as well as the measured machining outputs. OSs values are set as " 1 " for conventional experiments, and "2" for UAT experiments with a frequency of $18 \mathrm{kHz}$, and "3" for experiments performed at a frequency of $20 \mathrm{kHz}$. Furthermore, the total production costs per each run have been included while performing the sustainability analysis of the current experiments. The production cost includes 4 elements which are; machining costs $\left(\mathrm{C}_{\mathrm{m}}\right)$, cutting tool costs $\left(\mathrm{C}_{\mathrm{t}}\right)$, cooling and lubrication fluids cost $\left(\mathrm{C}_{\mathrm{CLF}}\right)$, and cost of electrical usage $\left(\mathrm{C}_{\mathrm{E}}\right)$ i.e., energy consumed by machine tool + energy consumed in generating ultrasonic vibrations for the tool.

The sustainability assessment steps are summarized in Fig. 14. The overall sustainability assessment index for each run has been calculated based on all previous considerations. The sustainability assessment results for the three studied cases are provided as shown in Fig.15(a). It can be seen that UAT with either frequency of $18 \mathrm{kHz}$ or $20 \mathrm{kHz}$ has shown better results than the conventional approach. Also, it is found that case I $(20 \mathrm{kHz})$ provided better results than case II $(18 \mathrm{kHz})$ at the lowest cutting speed level. However, at cutting speed of $40.7 \mathrm{~m} / \mathrm{min}$ or $61.14 \mathrm{~m} / \mathrm{min}$, case II showed the highest TWSI, which means the best performance in terms of machining outputs as well as sustainable indicators. The highest TWSI has been noticed at run\#1 using UAT with a frequency of $20 \mathrm{kHz}$, the TWSI was about 0.94 . This test has been performed at cutting 
speed of $27.1 \mathrm{~m} / \mathrm{min}$, feed rate of $0.11 \mathrm{~mm} / \mathrm{rev}$ and depth of cut of $0.1 \mathrm{~mm}$. A comparison between the highest TWSI values is provided in Fig. 15(b). At the case, the highest TWSI was about 0.79 at test \#19- Case II, which has been performed at cutting speed of $61.1 \mathrm{~m} / \mathrm{min}$, feed rate of $0.11 \mathrm{~mm} / \mathrm{rev}$ and depth of cut of 0.1 $\mathrm{mm}$. Similarly, for case 3, the highest TWSI was about 0.44 at test \#19-case III. In order to validate the effectiveness of the employed assessment model, a comparison between the optimal and predicted response values (i.e. $R_{a}$ and $\mathrm{P}$ ) was established in Table 5.

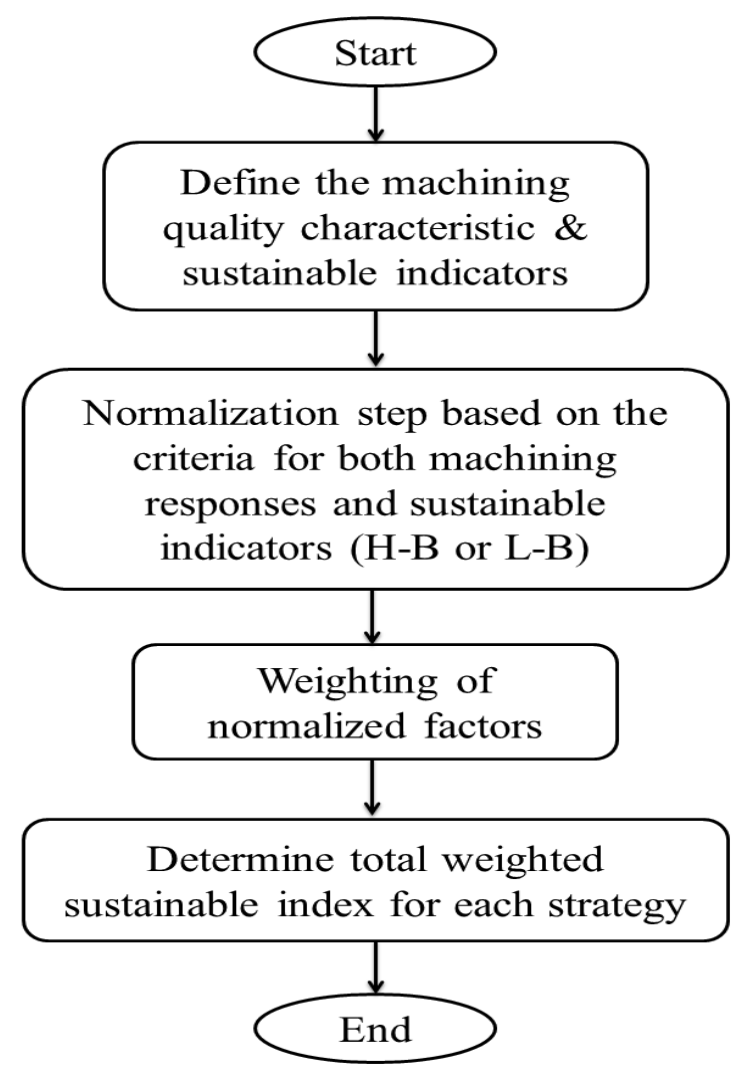

Fig.14 The steps of the sustainability assessment model 


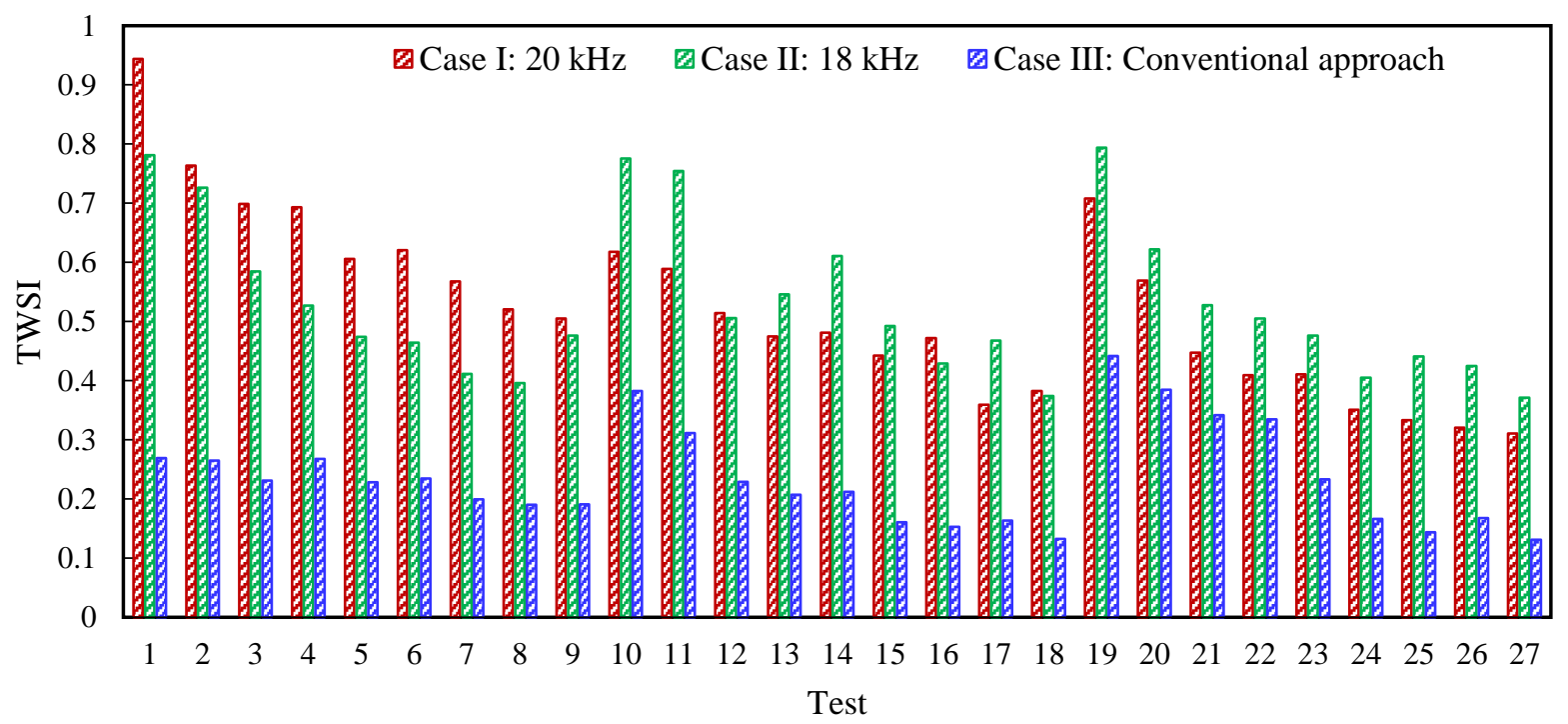

Fig.15 (a) Assessment results for the three studied cases

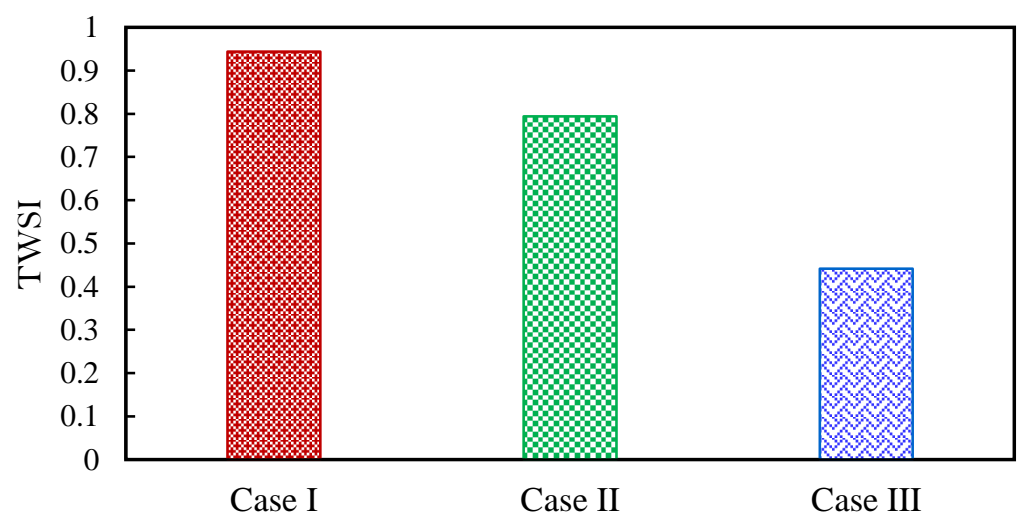

Fig.15 (b) A comparison between the three studied cases (highest TWSI values)

It should be stated that identical values are observed between the predicted and optimal values in terms of the $R_{a}$ results for the three studied cases. Regarding $P$, an acceptable agreement is noticed in Table 5 as this assessment model is mainly focused on establishing a balance between the machining outputs and the studied sustainability aspects, and it is a valuable tool to optimize the machining processes performance with considering the sustainability effectiveness. In the future, more details can be added to the current assessment model such as using more sustainable indicators related to waste management and applying sensitivity analysis along with using different weighting factors for the employed outputs and sustainable indicators.

Table 5 A comparison between the predicted and optimal machining outputs

\begin{tabular}{|l|c|c|}
\hline & \multicolumn{2}{|c|}{ Case I (20 kHz) } \\
\hline Response parameters & Predicted values (model) & Optimal values (experiments) \\
\hline
\end{tabular}




\begin{tabular}{|c|c|c|}
\hline $\mathrm{R}_{\mathrm{a}}(\mu \mathrm{m})$ & $0.37 \mu \mathrm{m}$ at experiment \#1 & $0.37 \mu \mathrm{m}$ at experiment \#1 \\
\hline Power consumption $(\mathrm{kW})$ & $288.67 \mathrm{~W}$ at experiment \#1 & $256 \mathrm{~W}$ at experiment \#16 \\
\hline & \multicolumn{2}{|c|}{ Case II (18 kHz) } \\
\hline Response parameters & Predicted values (model) & Optimal values (experiments) \\
\hline $\mathrm{R}_{\mathrm{a}}(\mu \mathrm{m})$ & $0.38 \mu \mathrm{m}$ at experiment \#19 & $0.38 \mu \mathrm{m}$ at experiment \#19 \\
\hline Power consumption $(\mathrm{kW})$ & $351.33 \mathrm{~W}$ at experiment \#19 & $279 \mathrm{~W}$ at experiment \#17 \\
\hline Response parameters & \multicolumn{2}{|c|}{ Case III (Conventional approach) } \\
\hline $\mathrm{R}_{\mathrm{a}}(\mu \mathrm{m})$ & Predicted values (model) & Optimal values (experiments) \\
\hline Power consumption $(\mathrm{kW})$ & $0.58 \mu \mathrm{m}$ at experiment \#19 & $0.58 \mu \mathrm{m}$ at experiment \#19 \\
\hline
\end{tabular}

\section{Conclusions}

This work presents machinability study of Nimonic-90 using UAT set-up. The set-up is developed in-house for small and medium scale industries. The critical component of the set-up is to design and fabrication of ultrasonic horn by selecting the suitable material and dimensions. The design of ultrasonic horn has been done analytically and validated by using FEM. However, some frequency loss also occurred due to the damping effect, but this loss was negligible. Comprehensive analysis of surface roughness, power consumption, and chip formation along with sustainability assessment has been carried out. FEM of UAT and $\mathrm{CT}$ has also been done along with the experiments. The following conclusions can be drawn:

- The UAT leads to a 75-80\% reduction in $R_{a}$ than CT because of the intermittent cutting action of the tool at $27.1 \mathrm{~m} / \mathrm{min}$ of cutting speed. As the cutting speed increases, the $R_{a}$ increases slightly as the TWCR increase in UAT, whereas it decreases in a CT.

- As the frequency increases, the $R_{a}$ decreases due to lower value of TWCR at higher frequency.

- As the feed rate increases, the $R_{a}$ increase in UAT and CT processes. However, the value of $R_{a}$ is $80 \%$ lower in the case of UAT due to its intermittent cutting action.

- As the depth of cut increases, the $R_{a}$ increases in UAT and CT processes. However, the reduction in $R_{a}$ is $60 \%$ in the case of the UAT process.

- The UAT process shows 6-15\% reduction in power consumption $(P)$ as compared to CT process.

- The chips formed during UAT were smooth, thin and have a shorter length as compared to CT because of repeatedly separating action of the cutting tool and work-piece.

- Finite element modeling results show the quasi-static nature of the stresses induces during the UAT process, which causes lower power generation during UAT process.

In addition, a sustainability assessment model is implemented to investigate the effect of UAT in terms of machining performance and sustainability effectiveness in a single integrated approach. In order to validate the effectiveness of the employed assessment model, a comparison between the optimal and predicted response values (i.e. $R_{a}$ and $P$ ) was established. It should be stated that identical values are observed between the predicted and optimal values in terms of the $R_{a}$ results for the three studied cases. Regarding the power consumption, an acceptable agreement was noticed as this assessment model is mainly focused on establishing a balance between the machining outputs and the studied sustainability 
aspects, and it is a valuable tool to optimize the machining processes performance by considering the sustainability effectiveness. Moreover, it was found that that UAT with either frequency of $18 \mathrm{kHz}$ or 20 $\mathrm{kHz}$ has shown better result than the CT approach. The highest TWSI has been noticed at run 1 using UAT with frequency of $20 \mathrm{kHz}$, the TWSI was about 0.94 . This test has been performed at cutting speed of $27.1 \mathrm{~m} / \mathrm{min}$, feed rate of $0.11 \mathrm{~mm} / \mathrm{rev}$ and DOC. of $0.1 \mathrm{~mm}$. It should be stated that the experimental studies performed to provide valuable machining data about the machinability of Nimonic 90 alloy. This data will assist researchers/practitioners in this area to develop numerical models in determining optimal machining parameters.

\section{Acknowledgments}

The authors are grateful to the Government of Gujarat for the funding to set up state-of-the-art manufacturing facilities at Advanced Manufacturing Laboratory, IITRAM. Authors are also thankful to Prof. Uday S. Dixit (Indian Institute of Technology - Guwahati) for his valuable comments.

\section{References}

[1] Kumar K, Singh V, Katyal P, Sharma N (2019) EDM $\mu$-drilling in Ti-6Al-7Nb: experimental investigation and optimization using NSGA-II Int J Adv Manuf Technology https://doi.org/10.1007/s00170-019-04012-6.

[2] Dhananchezian M, Rajkumar K (2020) Comparative Study of Cutting Insert Wear and Roughness Parameter $\left(R_{a}\right)$ while turning Nimonic 90 and Hastelloy C-276 by Coated Carbide Inserts. Materials Today: Proceedings 22:1409-1416.

[3] Venkatesan K, Devendiran S, Sachin D, Swaraj J (2019) Investigation of machinability characteristics and comparative analysis under different machining conditions for sustainable manufacturing, Measurement: 107425.

[4] Pervaiz S, Anwar S, Qureshi I, Ahmed N (2017) Recent Advances in the Machining of Titanium Alloys using Minimum Quantity Lubrication (MQL) Based Techniques. https://doi.org/10.1007/s40684-019-00033-4.

[5] Chetan, Ghosh S, Rao PV (2019) Comparison between sustainable cryogenic techniques and nano-MQL cooling mode in turning of nickel-based alloy. Journal of Cleaner Production 231:1036-1049.

[6] Khanna N, Airao J, Gupta MK., Song Q, Liu Z, Mia M, Maruda R, Krolczyk G (2019) Optimization of Power Consumption Associated with Surface Roughness in Ultrasonic Assisted Turning of Nimonic-90 Using Hybrid Particle Swarm-Simplex Method. Materials 12:3418.

[7] Khanna N, Agrawal C, Gupta MK, Song Q, Singla AK (2020) Sustainability and machinability improvement of Nimonic-90 using indigenously developed green hybrid machining technology. Journal of cleaner production 263:121402.

[8] Sharma N, Kumar K (2020) Investigation on Spark Erosion Machining Induced Surface Integrity of Super-Alloys. Springer DOI: https://doi.org/10.1007/978-3-030-18854-2_6.

[9] Singh H, Kumar V, Kapoor J. (2020), Optimization of WEDM process parameters in machining Nimonic 75 alloy using brass wire, Multidiscipline Modeling in Materials and Structures, https://doi.org/10.1108/MMMS-10-2019-0178.

[10] Davim JP, (2014) Machining of Titanium alloys, Springer,.

[11] Ahmed N, Mitrofanov AV, Babitsky VI, Silberschmidt V (2008) Analysis of material response to ultrasonic vibration loading in turning Inconel 718, Materials Science and Engineering, 424: 318-325.

[12] Maurotto A, Muhammad R, Roy A, Babitsky VI, Silberschmidt VI (2012) Comparing machinability of Ti-15-3-3-3 and Ni-625 alloys in UAT. Procedia CIRP: 330-335.

[13] Ahmed N, Mitrofanov AV, Babitsky VI, Silberschmidt VV (2007) Analysis of forces in ultrasonically assisted turning. Journal of Sound and Vibration 308: 845-854.

[14] Maurotto A, Roy A, Babitsky VI, Silberschmidt VV (2013) Analysis of machinability of Ti- and Ni-based alloys. Solid State Phenomena 188:330-338.

[15] Maurotto A, Muhammad R, Roy A, Silberschmidt VV (2013) Enhanced ultrasonically assisted turning of a $\beta$-titanium alloy Ultrasonics 53:1242-1250. 
[16] Muhammad R, Maurotto A, Demiral M, Roy A (2014) Thermally enhanced ultrasonically assisted machining of Ti alloy. CIRP Journal of Manufacturing Science and Technology 7:159-167.

[17] Muhammad R, Ahmed N, Ullah H, Roy A, Silberschmidt VV (2018) Hybrid machining process: experimental and numerical analysis of hot ultrasonically assisted turning. Int J Adv Manuf Technology 97. https://doi.org/10.1007/s00170-018-2087-6.

[18] Bai W, Roy A, Sun R, Silberschmidt VV (2019) Enhanced machinability of SiC-reinforced metal-matrix composite with hybrid turning Journal of Material Processing Technology 268: 149-161.

[19] Feyzi T, Safavi SM, (2013) Improving machinability of Inconel 718 with a new hybrid machining technique Int J Adv Manuf Technology 66:1025-1030.

[20] Kahraman MF, Öztürk S (2019) Experimental study of newly structural design grinding wheel considering response surface optimization and Monte Carlo simulation. Measurement 147: 106825.

[21] Maurotto A, Roy A, (2014) Surface-roughness improvement in ultrasonically assisted turning. Procedia CIRP, 13:49-54.

[22] Muhammad R, Hussain MS, Maurotto A, Siemers C, Roy A, Silberschmidt VV (2014) Analysis of a free-machining $\alpha+\beta$ titanium alloy using conventional and ultrasonically assisted turning. Journal of Materials Processing Technology, 214: 906-915.

[23] Lin G, Zhong ZW (2006) Ultrasonic assisted turning of an aluminium-based metal matrix composite. International Journal of Advanced Manufacturing Technology 1077-1081.

[24] Babitsky V, Mitrofanov AV, Silberschmidt VV (2004) Ultrasonically assisted turning of aviation materials: simulations and experimental study Ultrasonics 42:81-86

[25] Patil S, Joshi S, Tewari A, Joshi SS (2014) Modelling and simulation of effect of ultrasonic vibrations on machining of Ti6Al4V. Ultrasonics, 54:694-705.

[26] Nath C, Rahman M (2008) Effect of machining parameters in ultrasonic vibration cutting. International Journal of Machine Tools and Manufacture, 48:965-974.

[27] Amini S, Aghaei M, Lotfi M, Hakimi E (2017) Analysis of linear vibration in rotary turning of AISI 4140 steel Int J Adv Manuf Technology DOI: 10.1007/s00170-017-0108-5.

[28] Amini S, Lotfi M, Paktinat H, Kazemiyoun M (2017) Characterization of vibratory turning in cutting zone using a pneumatic quick-stop device, Engineering Science and Technology, an International Journal 20:403-410.

[29] Habtamu A, Ghosh S, Rao PV (2017) Experimental study on Machinability of Inconel 718 Using Ultrasonic Vibration Assisted Turning, Proceedings of 10th International Conference on Precision,Meso,Micro and Nano Engineering (COPEN10):583-586.

[30] Bhushan RK (2013) Optimization of cutting parameters for minimizing power consumption and maximizing tool life during machining of Al alloy SiC particle composites Journal of Cleaner Production 39:242-254

[31] Nur R, Noordin MY, Izman S, Kurniawan D (2014) The Effect of Cutting Parameters on Power Consumption during Turning Nickel Based Alloy Advanced Materials Research 84:799-802.

[32] Carmita CN (2013) Optimization of cutting parameters for minimizing energy consumption in turning of AISI 6061 T6 using Taguchi methodology and ANOVA Journal of Cleaner Production:1-9.

[33] Aman A, Singh H, Kumar P, Singh M (2008) Optimizing power consumption for CNC turned parts using response surface methodology and Taguchi's technique- A comparative analysis Journal of materials processing technology 200:373-384.

[34] Kishawy H, Hegab H, Saad E (2018) Design for sustainable manufacturing: Approach, implementation, and assessment. Sustainability, 10(10):3604.

[35] Fahy F, Gardonio P (2007) Sound and structural vibration- radiation, transmission and response Elsevier ISBN 13: 978-0-12373633-8.

[36] Amin SG, Ahmed MHM, Youssef HA (1995) Computer-aided design of acoustic horns for ultrasonic machining using finite element analysis. Journal of material processing technology 55:254-260.

[37] Helmi AY (2016) Machining of stainless steels and super alloys, Wiley.

[38] Astashev VK, Babitsky VI, (2007) Ultrasonic Processes and Machines: Dynamics, Control and Applications, Springer Verlag.

[39] Ozturk S (2014) Machinability of Stellite-6 Coatings with Ceramic Inserts and Tungsten Carbide Tools Arab J Sci Eng 39:73757383 DOI: 10.1007/s13369-014-1343-9

[40] Ahmed K, Dolaimy AL (2016) Effect of cutting parameters on surface roughness in turning operations Al-Qadisiyah Journal For Engineering Sciences, 9.

[41] Smith GT (2008) Cutting tool technology : industrial handbook.springer.

[42] Khidhir BA, Mohamed B, Study of cutting speed on surface roughness and chip formation when machining nickel-based alloy Journal of Mechanical Science and Technology 24:1053-59.

[43] Davim PJ, Astakhov VP (2011) Machining of Hard Materials, Springer. 
[44]Zhou L, Li J, Li F, Xu X, Wang L, Wang G, Kong L (2017) An improved cutting power model of machine tools in milling process. Int J Adv Manuf Tech. DOI: 10.1007/s00170-016-9929-X

[45] Xu Y, Zou P, He Y, Chen S, Tian Y, Gao X (2016) Comparative experimental research in turning of 304 austenitic stainless steel with and without ultrasonic vibration Proc IMechE Part C:Journal of Mechanical Engineering Science 1-17.

[46] Khanna N, Shah P, Agrawal C, Pusavec F, Hegab H (2020) Inconel 718 machining performance evaluation using indigeniously developed hybride machining facilities: experimental investigation and sustainability assessment, Int. J. of adv manuf tech 106:4987-4999 https://doi.org/10.1007/s00170-020-04921-x.

[47] Mitrofanov AV, Babitsky VI, Silberschmidt VV (2004) Finite element analysis of ultrasonically assisted turning of Inconel 718. Journal of Materials Processing Technology 153-154: 233-239

[48] Hegab HA, Darras B, Kishawy HA (2018) Towards sustainability assessment of machining processes. Journal of cleaner production, 170:694-703.

[49] Narita H, Desmira N, Fujimoto H (2008) Environmental burden analysis for machining operation using LCA method. In Manufacturing Systems and Technologies for the New Frontier Springer, London 65-68. 